\title{
Campus Open-Access Policy Implementation Models and Implications for IR Services
}

\section{Citation}

Finnie Duranceau, Ellen, and Sue Kriegsman. 2015. "Campus open-access policy implementation models and implications for IR services." In Making Institutional Repositories Work, ed. Burton B. Callicott, David Scherer, and Andrew Wesolek, Charleston Insights in Library, Archival, and Information Sciences, 87-105. West Lafayette, IN: Purdue University Press.

\section{Permanent link}

http://nrs.harvard.edu/urn-3:HUL.InstRepos:23503499

\section{Terms of Use}

This article was downloaded from Harvard University's DASH repository, and is made available under the terms and conditions applicable to Other Posted Material, as set forth at http:// nrs.harvard.edu/urn-3:HUL.InstRepos:dash.current.terms-of-use\#LAA

\section{Share Your Story}

The Harvard community has made this article openly available.

Please share how this access benefits you. Submit a story.

Accessibility 
Campus Open-Access Policy Implementation Models and Implications for IR Services

\section{Ellen Finnie Duranceau and Sue Kriegsman}

Implementation of campus open-access policies in the United States is still a relatively new-though increasingly widespread-activity. According to the Registry of Open Access Repositories Mandatory Archiving Policies (ROARMAP), U.S. campus policies have grown to include 73 campuses $^{1}$ (Figure 1), with steady increases since 2009, when the Harvard Faculty of Arts and Sciences adopted the first such policy in the United States. There was particularly dramatic growth in 2013, the last complete year measured.

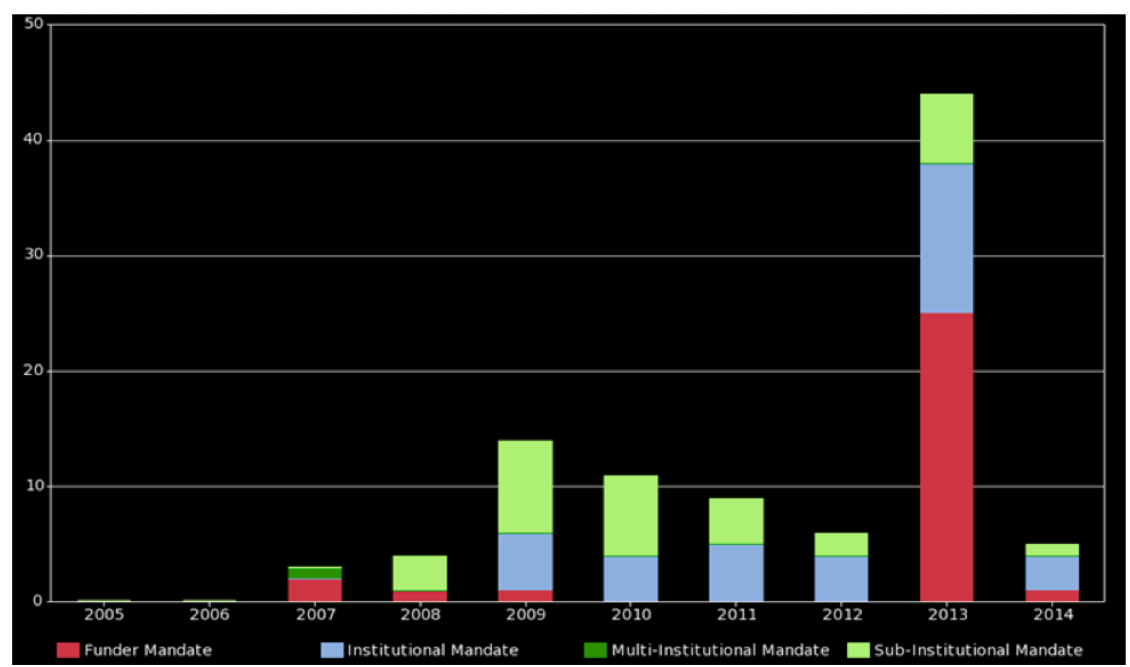

Figure 1: Open-access policies in the United States as of July 2015, from ROARMAP, Registry of Open Access Repositories Mandatory Archiving Policies, at http://roarmap.eprints.org/

While short summaries of some individual libraries' approaches to implementing these policies have begun to be published, ${ }^{2}$ a sense of the overall landscape of policy implementation has only begun to emerge.

As more campuses adopt open-access policies, sharing implementation methods and models is increasingly critical. As Shannon Kipphut-Smith notes in her summary of Rice University's implementation experience, libraries faced with the need to set up brand-new procedures find themselves in a "nuanced" environment without a roadmap. Their library, like others implementing policies, "had never before conducted activities similar to the implementation of the OA policy," so they found that "practically every activity has been experimental."3

Here, in attempt to build that needed roadmap, we provide a snapshot of the openaccess policy implementation landscape by evaluating data from a survey of Coalition of Open Access Policy Institutions (COAPI) and characterizing each library's OA policy implementation models for its campus. We reflect on implications for services associated with campus institutional repositories (IRs) in 
meeting implementation needs, identifying relevant IR services that have emerged in relation to, and in support of, each of the implementation models.

\section{Open-Access Implementation Models}

The Coalition of Open Access Policy Institutions (COAPI) surveyed its members in early 2014 about the scope of their policies and implementation details. COAPI generously made the resulting survey data available for this chapter. Our analysis of the survey data confirmed anecdotal impressions that open-access policy implementations on campuses in the United States tend to follow one or more of four models we have identified: systematic recruitment; targeted or opportunistic outreach; use of a faculty profile tool; and harvesting from other sites. We define each of these models below and provide examples from the campuses that responded to our follow-up inquiry to the COAPI survey, asking for feedback about our categorization of implementation models. ${ }^{4}$

\section{Systematic Recruitment by Liaisons or Other Staff}

The systematic recruitment approach involves the library, or a related department, gathering or obtaining metadata on faculty publications, and then using it to perform systematic outreach, usually through subject liaisons, to request and acquire publications from all campus departments.

Columbia, Harvard, Florida State, Lafayette, Massachusetts Institute of Technology (MIT), University of Rhode Island (URI), and Wellesley are characteristic examples of this approach. Princeton is building planned workflows based on the expectation that this will be a major implementation approach as well. Duke reported this as a secondary approach; Emory's plans track this model; and Kipphut-Smith refers in her article to some outreach efforts of this kind at Rice.

\section{Relevant IR Services}

An IR-based service that several campuses, including Harvard and MIT, are using to support this kind of systematic recruiting is the provision of author usage statistics. Download data for the author's papers is sent to authors, often when requesting additional manuscripts. This is seen as a tool that can incentivize deposits. Along with aggregated download from individuals, groups, or departments, or the number of visitors to the IR, the data can be automatically collected and shared to encourage authors to participate by depositing papers in the IR. MIT's service ${ }^{5}$ allows authors to $\log$ in to see their own article download statistics; aggregated download data for MIT's departments, labs, and centers are available through a public view. At Harvard, download statistics are automatically e-mailed to authors on a monthly basis and used to create a visualization showing the dissemination of the openaccess works available through the repository (see Figure 2). 


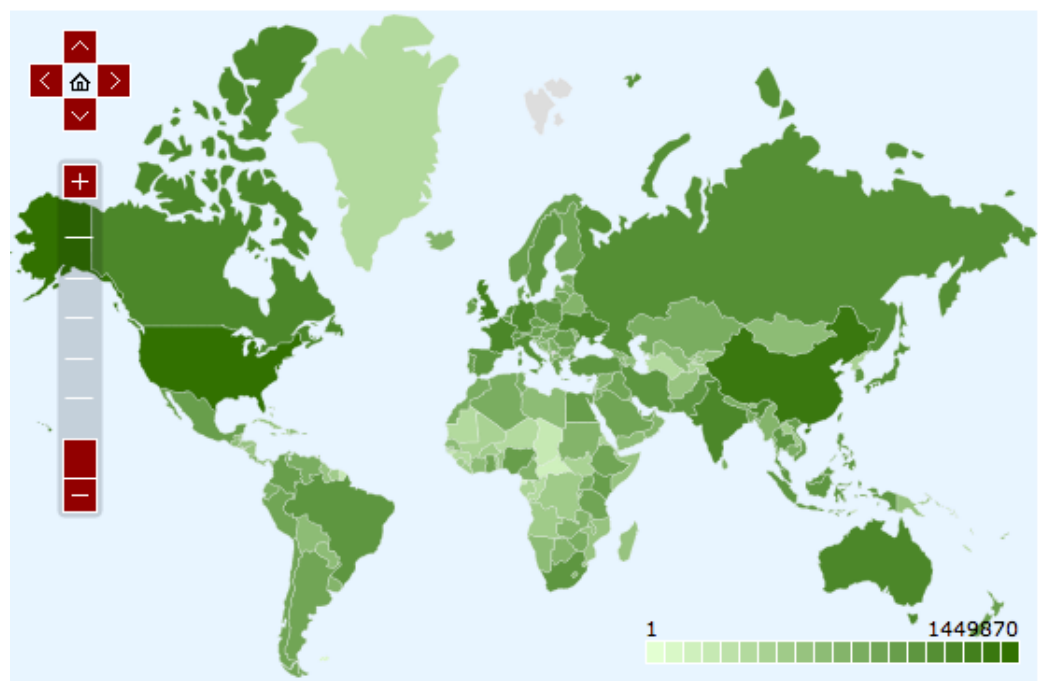

Figure 2: Harvard repository (DASH) download heat map at https://osc.hul.harvard.edu/dash/mydash?v=geomap\&gi=alldash \&t=1\&p=alltime

A heat map shows downloads of all the works deposited in the Harvard repository, Digital Access to Scholarship at Harvard (DASH). Libraries have received anecdotal feedback from authors that this kind of world map, whether for all works in the repository or for a single author or work (see Figure 3), encourages authors to contribute articles, because it demonstrates the need for access as well as the breadth of access possible with OA. For authors, the heat map brings the OA policy to life.

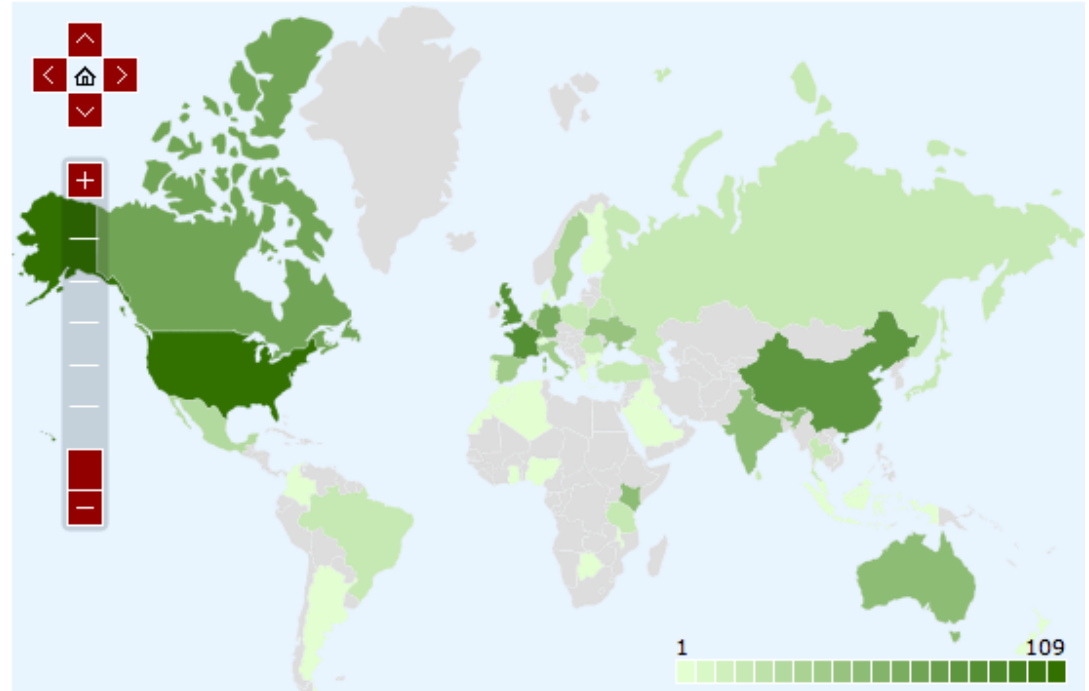

Figure 3: Harvard repository (DASH) download heat map for an individual article.

\section{Targeted and Opportunistic Outreach}

In this approach, specific departments or faculty are targeted with requests for papers; the approach is not broadly systematic, but tends to focus on departments that are perceived as more receptive. Nine campuses reported using this model, including Caltech, Columbia, Connecticut College, Duke, Emory, Florida State, Oberlin, University of Kansas, and Washington University, with the latter two 
campuses using this as their primary model. At Emory, this model has included, in the past, CV reviews for faculty with associated deposits. Florida State has found this model most successful when drawing on personal connections and when targeting research centers or institutes, rather than departments.

The main reasons cited for adopting this model were reported to be a lack of staff sufficient to implement a more systematic approach, or having used this as a secondary approach where a particular opportunity emerged (as with Caltech).

A specific subset of this model, using news reports to target outreach, is being successfully used at Caltech, Columbia, Duke, Lafayette, and MIT; Florida State is beginning to build this kind of connection. Both Duke and MIT use this approach where, in partnership with the campus news office, the news office notifies the library about research-related stories, and the library follows up by requesting the manuscript from the author so that the article can be made openly accessible via a link from the news story to the repository. Columbia has a similar workflow in partnership with their Public Affairs Office.

At Caltech, the Library and Media Relations departments have been collaborating since May 2014 on incorporating IR links in press releases. George Porter reports: "Although it took years to establish a solid connection, the effort has been paying off for all parties and seems to be institutionalized at this point." ${ }^{6}$ Several sites have had the same experience-that it can take time and persistence to build these partnerships, but that they are highly productive once established.

\section{Relevant IR Services}

Targeted outreach is particularly well suited to social media-based marketing efforts like this kind of connection with campus news services. Such a connection allows for an unusually compelling kind of outreach to authors, connecting with them when their work is being highlighted in the news-a time when they are particularly likely to want to share the relevant work widely.

At MIT and Duke, the campus news service links from their story to the paper available in the repository as a way of making the work openly accessible for all readers of the news story. MIT and Duke find authors quite receptive to providing their papers when their research is being discussed in the news. In the first four months of a pilot program, MIT acquired well over 40 papers for the IR that had not otherwise been available for the IR, or deposited.

Harvard has supported this mutually beneficial relationship with the campus news services by creating an automated feed from their IR, offering it to Communications and other departments. This helps raise awareness of research coming from the institution; and campus news services value having a permanent link to the $\mathrm{OA}$ article, which the repository can provide, in addition to the link to the published version. 
Social media approaches are not limited to news stories. Harvard is also generating Twitter feeds from the IR with links to recently deposited articles, as a quick and simple way to raise awareness about the research and to encourage authors to contribute articles. Similarly, Caltech and University of Washington offer RSS or Atom feeds to share deposit information.

Several institutions, including Connecticut College, Harvard, MIT, University of Rhode Island, and Washington University have "Top 10" lists for the most downloaded articles from their repository, or a list of recent submissions on the IR landing page. At URI, they also send a "congratulations" e-mail to all faculty each month, highlighting the top three most downloaded open-access policy articles in the last month. Andree Rathemacher reports: "This seems to have gotten some positive attention and no one has complained about spam." ${ }^{\prime 7}$

Another social media approach being used by several campuses (including MIT and Harvard) is collecting comments from readers of papers in the repository. The idea, at least for U.S.-based implementations, seems to have originated with Sean Thomas, the repository services program manager at MIT, who, inspired by a similar approach at MIT's OpenCourseWare, suggested a simple method to enable campuses to learn how and why people are using articles in their repositories under OA policies. Each paper includes a cover sheet with metadata about the paper and a "Share your Open Access story" link, which allows readers to describe how the access affects or benefits them. ${ }^{8}$

MIT consistently receives messages of thanks and compelling stories about access needs through this Web form ${ }^{9}$ (see Figure 4). One typical response was from a researcher in Nepal:

I am an independent researcher from a third world country not affiliated to any university or a company. Thus I neither have access to paid journals nor I can afford them. MIT's Open Access is something I love and rely upon.... Thank you again for thinking about the unfortunates and keeping the information free and open.

Another campus implementing this idea receives between 50 and 70 stories every month-from real people, reading and benefiting from open-access articles. 


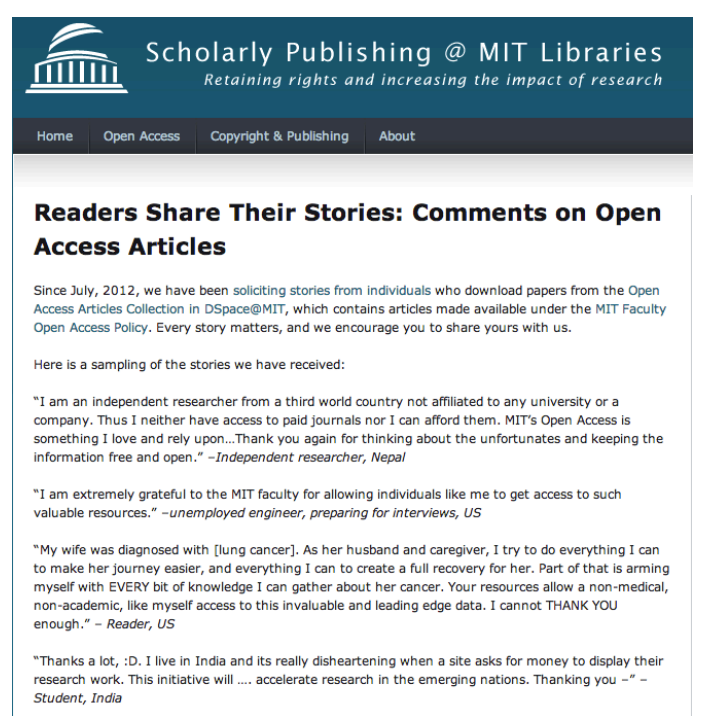

Figure 4: MIT Libraries' Web page of reader comments on open-access articles.

Stories can be shared on Web pages, on the IR landing page, through videos, ${ }^{10}$ and with the author of the original article, particularly if campuses are careful to protect confidentiality and ask for permission to share names and comments. This is a unique benefit of OA materials distributed from a repository; it's not always possible for authors to receive such personal feedback about the impact of their work. Whether as part of targeted or systematic outreach, sharing such stories can offer a strong incentive for authors to deposit papers, and provides an ongoing and very real demonstration of the value of making the papers open access.

With a small amount of review and editing, these stories can become an automated feedback loop for authors on how their OA articles have impacted readers. The stories can also be used in marketing campaigns. For example, Harvard used these stories for Open Access Week 2013 publicity and posters (see Figure 5). 


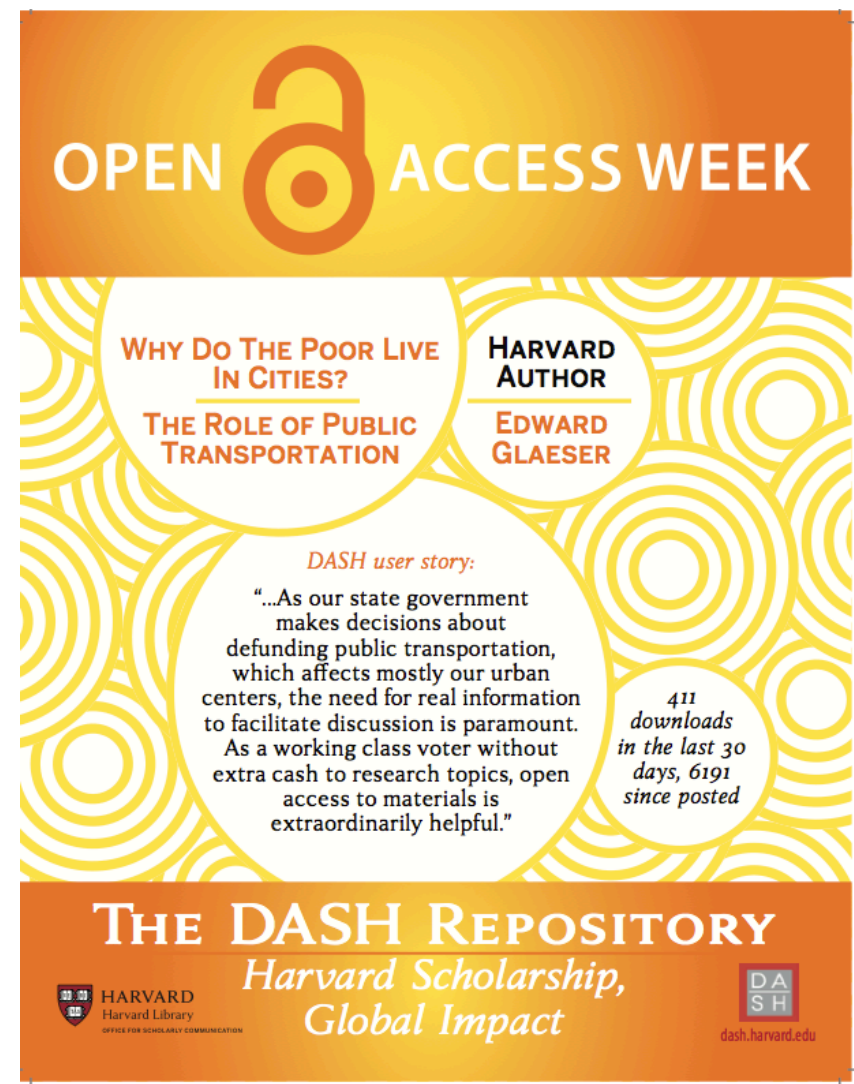

Figure 5: Harvard OA Week poster featuring reader comments from "Share Your Story" link.

\section{Use of Faculty Profile Tool}

In this approach, faculty outreach is mediated at least in part by a researcher profiling or bibliography tool, through which faculty are responsible for reviewing and/or adding metadata for-and uploading - their papers. Use of such a tool (e.g., Symplectic Elements) allows for unmediated deposit, with faculty managing their metadata and uploading papers. In all cases, these tools are being used internally only, not for public-facing profiles (though some campuses, such as Duke, feed data from their internal profiling tool into a public-facing profiling service, VIVO.) Most campuses that use a profiling tool reported using a commercial system, but Florida State has been leveraging a homegrown system on their campus, which contains CV information.

Implementing an open-access policy by using other campus reporting or profiling tools offers clear efficiencies and the potential for avoiding redundancies in data collection. For this reason, campuses do generally seek a means of connecting openaccess policy implementation with any campus systems that track and report on faculty publications. Neil McElroy of Lafayette could be speaking for many campuses when he comments that "it's possible we can find a workflow whereby the faculty's reporting of their publications to the Provost's Office is done by depositing eligible publications in the digital repository." 11 
Some campuses are already moving in that direction; for example, Kansas has been working with their university's Digital Measures application. Duke is the only campus currently reporting this approach as the primary implementation method (though they make use of all methods described here). Duke looks to more fully using the functionality of their Symplectic Elements system: "the Elements tool that we are using harvests metadata, and for sources that it can identify as being open access, provides one-click functionality to retrieve the item and deposit it in our local repository." They hope to begin "retrieving and depositing publications systematically through this process."12

Other campuses are also using profiling tools: Caltech (as a secondary strategy), Emory, Oberlin, the University of California (UC), and the University of Kansas, which focused originally on targeted outreach but which recently began using a campus profiling system as part of their implementation as well. At Emory, they are just now transitioning to the use of Symplectic Elements, which has been implemented in the School of Medicine and will be rolled out to other schools on campus. The University of California has just begun implementing their policy using this method. They will be sending out e-mail alerts asking faculty to confirm harvested metadata and to upload the full text of their articles.

\section{Relevant IR Services}

Institutions can use article-level metadata from their institutional repository to populate other campus systems, such as a faculty activity report or faculty profile tool. Faculty in the Harvard Faculty of Arts and Sciences, for example, are required to complete a Faculty Activity Report each year through a reporting tool. Harvard hopes to prepopulate that tool with data from the Harvard repository, which would prevent the faculty, or faculty assistants, from having to rekey information into the annual report, providing significant efficiencies. At Emory, articles from their repository OpenEmory were used, as Lisa Macklin reports, "as a way to prepopulate faculty profiles in Elements because we had already verified the citations and authorship of the articles in the repository."13 UC has plans to "integrate our Elements system with the [public-facing] faculty profile projects throughout the UC campuses,"14 and they are working on that now. Duke has also built connections between the profiling tool and the IR, and they find this mechanism is more meaningful for authors than the concept of an "IR": "Having the OA repository links directly in the faculty profiles is something we're pretty proud of, as it makes it easier for authors to see the connection between uploading their work and having it be associated directly with them, rather than with an institutional repository, which is kind of an abstract idea to most people who aren't librarians." As Duke's Paolo Mangiafico stresses, with authors and researchers seeking from places such as Google, Google Scholar, an organization's Web site, or a researcher's profile, the IR becomes "the ultimate destination, but not the starting point." 15

These integrations of IR data with other campus tools create efficiencies and reduce redundancy when managing and sharing publication data on campus, and help lead 
readers to the information in the IR without expecting the IR to be a known source that is sought in and of itself.

\section{Harvesting}

Harvesting involves automatically, semiautomatically, or manually copying manuscripts or published versions from repositories or publisher sites. Eleven campuses report using this method, though only one, Caltech, indicates it is their primary implementation model. Some campuses such as Columbia and MIT have implemented automated deposit into their repository for some articles, including, for example, SWORD deposits of BioMed Central articles; ${ }^{16}$ other campuses are collecting papers from resources such as Creative Commons-licensed journals, PubMedCentral (where permissible), or other repositories that allow copying. UC harvests some articles through Symplectic Elements, though primarily this service grabs only metadata.

Emory's and Harvard's approaches to harvesting focus on the open-access subset of PubMedCentral. Emory has a script that uses an API provided by the National Library of Medicine that "brings back metadata or the article (if [the] article is published with a CC license) for articles authored by someone at Emory." 17 These are reviewed and then deposited if the articles are CC licensed.

\section{Relevant IR Services}

Automated deposit is a labor-saving repository service that supports a harvesting approach for implementation. Campuses like Columbia and MIT that are taking advantage of this option benefit from automatically supplied metadata and reduced steps in handling article deposits. Deposits are also more timely: identification of relevant articles for a given repository is generally handled by the publisher and is very current.

Many campuses, including MIT, are watching the evolution of the Sponsoring Consortium for Open Access Publishing in Particle Physics (SCOAP ${ }^{3}$ ) repository service that will allow harvesting articles automatically for deposit into the campus repository, and have plans to use this service. As part of the $\mathrm{SCOAP}^{3}$ commitment to making high-energy physics articles openly accessible, the European Organization for Nuclear Research, known as CERN, has established a repository to house the articles included in the program. CERN promised that SCOAP ${ }^{3}$ library partners will "have the option to automatically populate their institution's digital repository with the SCOAP 3 peer-reviewed articles." 18 As of July 2014, it was announced that the $\mathrm{SCOAP}^{3}$ repository was "open for the community to harvest content through OAIPMH feeds." 19

\section{Discussion: Factors Influencing Choice of Implementation Model}

In general, the campus context is influential in determining which implementation models are adopted. For example, campuses where a faculty profile tool has been 
implemented have a means of collecting papers under their open-access policies not available to other campuses. While rolling out such tools may involve coordination with the library, as is the case with Kansas, where the library participated in early discussions, for the most part being able to leverage a profiling tool as a means of engaging faculty is determined by the presence of an existing broader campus initiative (as at Duke and Emory).

The main reasons cited for adopting the targeted and opportunistic approach are a lack of staff to take a more systematic approach, or having adopted this as a secondary approach where a particular opportunity emerged (as with Caltech). Connecticut College and Kansas report using this model while building toward a more systematic approach, particularly as more staff become available. Other campuses, such as Columbia, follow this targeted model when a policy doesn't apply to all authors on campus, using more focused outreach for departments where a policy is still in development. Columbia notes that this approach can help build a base of support for a possible future policy, in that it can demonstrate that "the work required from them is minimal while the benefits of their content within the IR are clear." 20

At Emory, they began with a focus on harvesting and targeted outreach, but they are transitioning to the use of a profiling tool. As Lisa Macklin reports, "Our main reason for making the change mid-stream is the opportunity tying into the faculty profiling tool will provide. When we held our Open Access Conversations with faculty as part of the process of adopting an OA policy, we consistently heard from faculty that they wanted deposit into the repository to be a part of the work they are already doing. By connecting the repository with the faculty profiling system, we have the opportunity for faculty to deposit content in the repository while reporting their annual activities." This shift is extremely important, for it integrates the repository and open access policy implementation into workflows that the faculty are already engaged in. As Lisa Macklin concludes, "Taking advantage of this opportunity to make the repository "simply a part of what faculty [already] have to do is where we all need to head if we can." 21

Campuses that have "permission-based" policies (like all those reported on here, with the exception of Florida State) also differ in the degree to which review of publisher policies informs their deposit strategy. One campus, for example, notes that they avoid depositing under the university's license through the policy "where the publisher prohibits it and the author failed (or didn't try) to secure permission by means of an author addendum prior to publication." Other campuses review publisher policies only where the license to the institution does not apply to the article (e.g., if there is no faculty author on the paper).

Many of these decisions emerge from the campus culture and resources, such as faculty preferences, administrative choices about services and tools that will be offered, risk tolerance, and staff or software development resources. While this chapter identifies various methods campuses could take to implement a policy, 
libraries need to operate within these specific institutional realities when making implementation decisions.

These models in some sense describe a set of progressive steps in a maturing implementation environment. For example, Kansas reported that they began with a targeted outreach, and then moved on to a faculty profiling tool when the provost's office implemented such a system, having brought the libraries in on the conversation early on; and they have now begun to build the resources and work processes necessary to adopt a harvesting approach.

Whatever methods a campus uses, the repository offers the possibility of increasing efficiency through data sharing, whether for campus systems that track publications, or for social media outlets that raise awareness about the research carried out on campus. Implementing an open-access policy thus provides new paths for leveraging the IR infrastructure, providing needed and relevant services on campus. At the same time IR services assist in bringing the open-access policy to life and enhancing policy implementation by providing usage data, reader stories, and other services that demonstrate the policy's impact and inspire authors to contribute papers.

\section{Conclusion}

Campus open-access policies have become more common in the six years since the Harvard Faculty of Arts and Sciences passed the first license-style policy in the United States, with growth surging in 2013. Thus, many libraries are now grappling with how best to implement their faculty's wish to share their work as openly as possible, and to identify best practices in implementing the specific terms of their campus's policy. A recent guide to good practices ${ }^{22}$ is an essential tool for libraries evaluating specifically how to create and implement a new policy; this current survey of campus policies provides a complementary view of the existing implementation environment. We have identified and described four main implementation models, offering a glimpse of an emerging - and still evolvinglandscape for open-access policy implementation in the United States.

The COAPI survey and our follow-up inquiries have confirmed that most campuses are using more than one of these methods, at times maturing from less systematic and more manual processes toward models that are more systematic (e.g., using a researcher profiling system to target all papers) or more automated (e.g., using the SWORD protocol or assistance from vended services like Symplectic Elements) to perform automatic repository deposits. Other campuses have shifted strategies based on the availability of additional staff for outreach, or access to new tools, such as the adoption of campus publication reporting systems.

A common thread among all of the campuses is the desire to meet author needs by building repository-related services around the deposited papers. These include integration with researcher profiling/bibliography tools and campus publication 
reporting systems; development of repository-based usage statistics tools and reports of reader impacts; and using repository links and information to partner with news and communication services on campus. No matter what implementation method a campus uses, we see from the examples provided here that campuses with open-access policies are using repository-related services to improve efficiencies in relation to their own campus policies, but also for funder or other administrative requirements, to support the social media presence, and to share data efficiently between systems.

Automatic harvesting and deposit are beginning to take hold and expand on some campuses. To make SWORD deposits more widely available and scalable, however, we will need to see advancement and success from projects like the $\mathrm{SCOAP}^{3}$ repository services and the JISC Open Access Repository Junction, ${ }^{23}$ which would establish an intermediary or "broker" to direct articles deposited by publishers or other repositories to the appropriate repositories. This kind of project makes it possible, in theory, for publishers to set up just one delivery mechanism - to the broker-rather than having to establish and maintain connections to every campus repository, which is unlikely to be sustainable. Such projects show the way toward a sustainable environment for sharing publications and supplementary material through campus repositories and more seamlessly complying with grant requirements.

With respect to grant requirements, the implementation of the 2013 White House directive on public access to data and publications ${ }^{24}$ will no doubt further shift the landscape we snapshot here. At the time of this writing, only one agency, the Department of Energy (DOE), has provided details of their implementation plan. The DOE's Public Access Plan ${ }^{25}$ requires the final accepted manuscript to be deposited in an open-access repository, and campus institutional repositories are well positioned to fulfill researcher obligations under this plan. Because the DOE is such a significant funder of U.S. research, this requirement is likely to create a new incentive for many authors to deposit their manuscripts in their local IR, particularly if the library is also able to support the DOE's metadata, accessibility, and interoperability requirements.

It remains to be seen whether campus open-access policies will continue to grow in number once campuses begin to grapple with implementing the U.S. government funder policies under this directive. Meanwhile, integrating our campus policy implementations with research funder requirements will be a key area of focus on our campuses, potentially initiating new implementation models and inspiring new repository services.

\section{Acknowledgments}

We gratefully acknowledge the following individuals and their institutions for providing information directly to us about their open-access implementations, in 
addition to their COAPI survey responses. This chapter would not have been possible without their generous participation.

- Andrew Wesolek, Coalition of Open Access Policy Institutions (COAPI) And:

- Alan Boyd, Associate Director of Libraries, Oberlin College

- Jane Callahan, Archivist, Wellesley College

- Ada Emmett, Scholarly Communications Librarian, The University of Kansas

- Ray English, Director of Libraries, Oberlin College

- Rebecca Kennison, Director, Center for Digital Research and Scholarship, Columbia University

- Anne Langley, Head Librarian, Science and Technology Libraries, Princeton University

- Ruth Lewis, Scholarly Communications Coordinator \& Science (Biology, Math, History of Science) Librarian, Washington University in St. Louis

- Yuan Li, Scholarly Communications Librarian, Princeton University (who also provided information on Syracuse University)

- Lisa Macklin, Director, Scholarly Communications Office, Robert W. Woodruff Library, Emory University

- Paolo Mangiafico, Coordinator of Scholarly Communications Technology, Duke University Libraries Office of Copyright \& Scholarly Communication, Duke University

- Neil McElroy, Dean of Libraries, Lafayette College

- Catherine Mitchell, Director of Publishing Services, University of California, California Digital Library

- Benjamin Panciera, Ruth Rusch Sheppe '40 Director of Special Collections, Connecticut College

- George Porter, Interim Head, Research and Information Services, Sherman Fairchild Library, California Institute of Technology (Caltech)

- Andree Rathemacher, Professor/Head, Acquisitions, University Libraries, University of Rhode Island

- Micah Vandegrift, Scholarly Communication Librarian, Florida State University

- Jen Waller, Scholarly Communication Liaison, King Library, Miami University (policy for librarians only)

Any errors are completely our own. 


\section{Appendix}

\section{Open Access Implementation Models Survey Results Matrix}

\begin{tabular}{|c|c|c|c|c|}
\hline & \begin{tabular}{|c|} 
Systematic \\
recruitment by \\
liaisons or other \\
staff
\end{tabular} & $\begin{array}{c}\text { Targeted and } \\
\text { opportunistic } \\
\text { outreach }\end{array}$ & $\begin{array}{l}\text { Use of faculty } \\
\text { profile tool }\end{array}$ & Harvesting \\
\hline Totals & 10 & 9 & 6 & 11 \\
\hline Caltech & & $\mathrm{x}$ & & $\mathrm{x}$ \\
\hline Columbia University & $\mathrm{x}$ & $\mathrm{x}$ & & $\mathrm{x}$ \\
\hline Connecticut College & & $\mathrm{x}$ & & \\
\hline Duke University & $\mathrm{x}$ & $\mathrm{x}$ & $\mathrm{x}$ & $\mathrm{x}$ \\
\hline Emory University & $\mathrm{x}$ & $\mathrm{x}$ & $\mathrm{x}$ & $\mathrm{x}$ \\
\hline Florida State University & $\mathrm{x}$ & $\mathrm{x}$ & $\mathrm{x}$ & \\
\hline Harvard University & $\mathrm{x}$ & & & $\mathrm{x}$ \\
\hline Lafayette College & $\mathrm{x}$ & & & \\
\hline MIT & $\mathrm{x}$ & & & $\mathrm{x}$ \\
\hline Oberlin College & & $\mathrm{x}$ & $\mathrm{x}$ & \\
\hline Princeton University & $\mathrm{x}$ & & & $\mathrm{x}$ \\
\hline University of California & & & $\mathrm{x}$ & $\mathrm{x}$ \\
\hline University of Kansas & & $\mathrm{x}$ & $\mathrm{x}$ & $\mathrm{x}$ \\
\hline University of Rhode Island & $\mathrm{x}$ & & & \\
\hline Washington University & & $\mathrm{x}$ & & $\mathrm{x}$ \\
\hline Wellesley College & $\mathrm{x}$ & & & $\mathrm{x}$ \\
\hline
\end{tabular}

\section{Endnotes}

${ }^{1}$ This total is for campuses, not department- or school-level policies on a single campus.

${ }^{2}$ See for example the discussion of the Rollins implementation in Miller, J. (2011). Open access and liberal arts colleges: Looking beyond research institutions. College \& Research Library News, 72(1), retrieved from http://crln.acrl.org/content/72/1/16; and Kipphut-Smith, S. (2014, Summer). Engaging in a campus-wide conversation about open access. Texas Library Journal, 90(2), 70-71, which describes some of the barriers to effective policy implementation at Rice's Fondren Library; and the authors' prior overview: Duranceau, E. F., \& Kriegsman, S. (2013). Implementing open access policies using institutional repositories. The Institutional Repository: Benefits and Challenges. Chicago: ALCTS, 81-105, retrieved from http://www.ala.org/alcts/sites/ala.org.alcts/files/content/resources/papers/ir_ch05_.pdf 
${ }^{3}$ Kipphut-Smith, S. (2014, Summer). Engaging in a campus-wide conversation about open access. Texas Library Journal, 90(2), 70.

${ }^{4}$ We sent inquiries to 18 campuses with a proposed characterization of their implementation model(s) based on the COAPI survey results. Our goal was to confirm our proposed scheme of implementation models and be sure we reflected each campus's approach accurately. The campuses' confirmed responses form the basis for the models and data discussed here. We excluded campuses whose policies were still in development or where the policy applied only to library staff.

5 MIT's service is accessible at oastats.mit.edu.

${ }^{6}$ George Porter, Interim Head, Research and Information Services, Sherman Fairchild Library, California Institute of Technology (Caltech), personal communication, October 17, 2014.

${ }^{7}$ Andree Rathemacher, Professor/Head, Acquisitions, University Libraries, University of Rhode Island, personal communication, October 20, 2014.

${ }^{8}$ See: http://libraries.mit.edu/forms/dspace-oa-articles.html

${ }^{9}$ See: http://libraries.mit.edu/scholarly/comments-on-open-access-articles/

10 See example of comments incorporated in a video from Harvard:

https://www.youtube.com/watch?v=7Ah86t49DI4\&list=PL2SOU6wwxB0suycszlpa2ltzbWqmYk2pg \&index $=1$

${ }^{11}$ Neil McElroy, Dean of Libraries, Lafayette College, personal communication, August 7, 2014.

12 Paolo Mangiafico, Director of Digital Information Strategy, Duke University, personal communication, August 7, 2014.

${ }^{13}$ Lisa Macklin, Director, Scholarly Communications Office, Emory, personal communication, October 23, 2014.

14 Catherine Mitchell, Director of Publishing Services, University of California, California Digital Library, personal communication, October 17, 2014.

15 Paolo Mangiafico, Director of Digital Information Strategy, Duke University, personal communication, August 7, 2014.

16 BioMed Central has been offering SWORD deposit at no extra cost to members (see: http://www.biomedcentral.com/libraries/aad). For a description of this process, see Duranceau and Rodgers: Automated IR deposit via the SWORD protocol: An MIT/BioMed Central experiment at http://uksg.metapress.com/content/1437x1631052407r/?p=f61c630cf6f54ae4bd16513a2cd180f4\& pi=11. SWORD stands for Simple Web-service Offering Repository Deposit.

${ }^{17}$ Lisa Macklin, Director, Scholarly Communications Office, Emory, personal communication, October 23, 2014.

18 See: http://scoap3.org/faq

${ }^{19}$ E-mail announcement to SCOAP3USA contacts list: "The SCOAP3 repository: OAI-PMH feed now available," July 18, 2014. And see: http://scoap3.org/news/the-scoap3-repository-oaipmh-feed-now-available.html

${ }^{20}$ Rebecca Kennison, Director, Center for Digital Research and Scholarship, Columbia University, personal communication, August 8, 2014.

${ }^{21}$ Lisa Macklin, Director, Scholarly Communications Office, Emory, personal communication, October 23, 2014.

22

See: Good practices for university open-access policies,

http://cyber.law.harvard.edu/hoap/Good_practices_for_university_openaccess_policies

${ }^{23}$ See: http://www.jisc.ac.uk/whatwedo/programmes/inf11/oarj.aspx

${ }^{24}$ Memorandum from the OSTP:

http://www.whitehouse.gov/sites/default/files/microsites/ostp/ostp_public_acces s_memo_2013.pdf

${ }^{25} \mathrm{http}: / /$ www.energy.gov/sites/prod/files/2014/08/f18/DOE_Public_Access\%20Plan_FINAL.pdf 
